\title{
Teachers' Values and Social Competences: Towards a Social Skills Modelling Definition
}

\author{
Lucia Bombieri, Ph.D. candidate \\ Research Intern at International laboratory for Socio-Cultural Research (www.scr.hse.ru) National Research \\ University Higher School of Economics, 101000 Moscow, Russia, Armyanskiy Per., 4/2, office 413 \\ Ibombieri@hse.ru
}

\begin{abstract}
:
The demands that teaching is exerting on school practitioners have substantially changed in the last two decades. One of the most challenging aspects arises from an extremely fluid composition of the student population, with a larger variety of ethnicities, cultural traditions, and religions than in the past. The goals have shifted, as well, and they extend well beyond the transmission of specific subject contents. But can teachers effectively help the coming generations to develop social skills and common values, allowing them to promptly react to scenarios which are impossible to foresee?

The aim of this review is to offer a coherent selection of previous findings related to the pivotal role of teachers at nurturing the moral acquisitions in their students. Four sections are dissecting evidence about teaching efficacy, teaching practice, value transmission and imitative learning. Through these elements, the possibilities of a successful intervention will be discussed and confronted with the unavoidable limitations and controversies.
\end{abstract}

Key words: teaching efficacy, teaching practice, value transmission, social skills, modelling

Date of Publication: 30.08.2018

DOI 10.24297/jssr.v12i2.7431

ISSN: 2321-1091

Volume: 12 Issue: 2

Journal: Journal of Social Science Research

Publisher: CIRWORLD

Website: https://cirworld.com

This work is licensed under a Creative Commons Attribution 4.0 International License. 


\section{Highlights:}

- Teachers' effectiveness is a dynamic multi-layered process

- Teaching actions exert a strong impact on students' outcomes

- Values and socio-emotional skills enhance teachers and students' well-being

- Students actively decode and embrace observed sets of behaviour

The author would like to acknowledge the priceless inspiration offered by several teachers who, through their leading by example, are infusing passion for knowledge and building cohesion in their classrooms.

The article was prepared within the framework of the Basic Research Program at the National Research University Higher School of Economics (HSE) and supported within the framework of a subsidy granted to the HSE by the Government of the Russian Federation for the implementation of the Global Competitiveness Program.

\section{Teachers' Values and Social Competences: Towards a Social Skills Modelling Definition}

The time when teaching meant just to transmit information and to grade assignments is long gone. Nowadays, teaching is one of the most stressful and constraining careers. Teachers are expected to be able to solve issues which have nothing to do with their own subject-expertise, mostly due to swift changes and the demands of a society which is continually evolving.

Education is a term that offers a broad range of definitions and introduces peculiar insights on several dynamics. Investigations in education have been performed in the field of economics (Gilead, 2017), politics (Gerrard, 2017), sociology (Flecha, 2011), pedagogy (Veiga-Neto, 2017), just to mention a few. Psychology is not a marginal contributor to the debate, as it will be thoroughly shown throughout this paper, challenging and modifying its own understanding and assumptions. Other viable routes focused on the main actors playing a role in the education process: students (Ryerson, 2017), teachers (Moses, Berry, Saab, Admiraal, 2017), parents (Hornby \& Blackwell, 2017).

The present paper stems from both these approaches and aims at examining the role of teachers as pivotal influencer, both individually and within a community, when applying their own set of human values and social competences for the benefit of their students, contributing to the building of a more harmonious and fruitful learning environment.

\section{Teachers' efficacy and effectiveness}

With the term "teacher efficacy", it is referred to attitudes about teachers' ability to teach and about students' ability to learn (Tschannen-Moran, Hoy, \& Hoy, 1998).

Teacher effectiveness is often used interchangeably because both constructs refer to reciprocal and cyclic occurrences between instructions and performances. The relationship between teachers' characteristics and students' outcomes has been widely explored and documented and it is considered one of the key points when trying to unfold this aspect of the teaching profession.

In order to quantify this connection, Hanushek and Rivkin (2010) produced an algorithm that measured the impact of teachers' interventions on final scores among the American school population. Despite the fact that they could not identify which element(s) within the teaching practice specifically weighted in, they were able to estimate these significant differences in effectiveness and the magnitude of teaching quality on grades. 
As a partial summary of what available in literature, it is worth mentioning the review of Reynold and colleague (2014). The authors offered a broad overview of the mounting body of research investigating Educational Effectiveness. Most notably, they found that the latest directions in the field are targeting a dynamic set of relationships which can be seen as formed by different levels, all interconnected and contributing - when not impeding - desirable outcomes (Kyriakides \& Creemers, 2008). In their model, they scrutinized several components of teaching, through a check list and a questionnaire. Not only were elements such as questioning, assessment, teacher-student relationship double measured via external observers and students' reports, they were also dissected in further five quantitative or qualitative levels according to their frequency, focus, stage, quality and differentiation. The design is quite complex and elaborated, so were the results and the following discussion. A critical argument that the authors offered is that each factor at classroom level cannot be reduced to one of its characteristics to fully understand their concurrence and facilitating effect on students' achievements and none is to be preferred tout-court.

Among the controversial results present in literature, some personal characteristics are sporadically recurrent when addressing teaching effectiveness. Personality traits, for instance, were found to be linked to how effective teaching performance is and how significant teachers' influence can be on their students' results in the study conducted by Rockoff and colleagues (2011). Nevertheless, there are conflicting findings and weak conceptual frameworks that suggest a more cautious position on the matter and encourage further studies in order to depict a more comprehensive scenario. Kim and colleagues (2018), for instance, investigated the influence of noncognitive aspects of teachers, measured through the Big Five Inventory Test, on subjective measures of efficacy (such as support) and academic achievement among secondary school students. The results pointed to a key assumption that three factors, namely consciousness, agreeableness and neuroticism, were valid predictors for the emotion-related outcomes. However, the personality characteristics of the teachers did not exert a discernible role in academic success which seems to be more resistant to short-term changes and is rooted solidly on the previous history of achievement rather than on the charisma of the educator. Similar findings were previously described by Patrick (2011) in her study on student evaluation of teaching in secondary education. Perceived likeability of the teachers or the course does not really affect the expected achievements. Thus, personality is often included in the investigations in combination with other variables (i.e. contexts and tasks) and has only been relevant when in addition to those other elements. Further investigation is still required before being able to draw a link between personality and effectiveness.

On a different level, when trying to put theory into practice it is crucial to rely on tools that can adequately identify and connect all these facets together. The operationalization of effectiveness has been tackled by Tschannen-Moran and Woolfolk Hoy (2001). They revised the existing scales and measurements, stemming from two main strands: Rotter's Locus of Control (1966) and Bandura's Social Cognitive Theory (1997). Furthermore, after dealing with the weaknesses of the scales which were available at the time, they elaborated a new questionnaire that tried to address previous measurements' limitations by including items that assess a broader range of teaching tasks, including instructional strategies, student engagement, and classroom management.

All these contributions have provided an ample and cohesive investigation into this specific aspect of what can be seen as the teachers' instructional role, both on a theoretical and methodological perspective.

\section{Teachers' practices or processes}

Classroom practices can be clustered around three main functions: giving instructions, providing tasks and delivering assessment.

First, instructions play a significant role when enhancing critical thinking. Marin and Halpern (2011) provided supporting evidence that explicit instructions, rather than embedded, increased final scores in high-school students who were starting to develop critical thinking skills. From a cognitive perspective to a social one, instructions have been linked to the reduction and the control of disruptive behaviours and to an increased level of peer-support within the classroom (Müller, Hofmann, Begert, and Cillessen, 2018). Teachers' 
instructions have been scrutinized in three components: their being academically supporting, interesting and differentiated. The main goal was to keep the students focused on their academic goals and avoid being too distracted pursuing other social goals (popularity and peer-interactions), thus interfering with the learning process.

A second relevant process performed by teachers and appraised by students is task selection. Studies in this matter have investigated self-reported students' perception, but it is undoubtedly a teacher's prerogative to select and administer the exercises, and consequently the choice of how to organize and deliver the activities during the lesson or in the afterwards. Supporting this interesting link between task choice and results, Nuutila and colleagues (2018) measured twice, in year 4 and year 6, the students' outcomes for Maths tests. While assessing different sub-domains, they found significative correlations between task interest, success expectancies and final results.

It should be made clear, however, that choosing any teaching approach, task and practice cannot be used as sole explanation for students' academic success or failure. As it has been discussed previously when referring to teachers' personal characteristics, there is no one ideal way to meet every student's needs. In their study, Kikas and colleagues (2014) discussed the different impact that student characteristics (in maths, reading and task persistence) and teaching styles (child-centred, teacher-directed and child-dominated) have on Maths and language performances within a sample of very young pupils in their first and second grade of primary school. Interpreting the different interactions between these two levels enabled the researchers not to categorically affirm which pedagogical approach was preferable overall, rather which combination of them was facilitating or impeding pupils' results. Even at this early stage in the school experience, it is fundamental to recognize how the teaching-learning dyad is a two-way process that works in a loop, and it requires from every side to systematically interpret the feedback and to adjust their strategies to meet further reciprocal requirements.

Finally, one of the teacher's core duties is assessment. Summative assessment is based on tests or assignments that are given at the end of a specific instructional period and whose results are converted and/or recorded as grades. It is widely present (but not exclusively) in almost every state school and at all levels: it is particularly useful if we consider how pressed in time and scrutinized is school staff nowadays because it provides the kind of documentation which is easy to collect, forming an objective ground for the marking process which can be conveniently shared with all the other agencies (families, administration, academy). However, Black and William (1998) effectively highlighted some notable findings through their work that designed and supported the socalled formative assessment, a collection of detailed information that can be used to improve instructions and learning strategies throughout the whole process. An important consideration is that teachers and students were providing constructive feedback to each other and, as a result, building meaningful interactions. This was a recurrent motive in several of the studies that they considered for this work. Moreover, the choice of formative assessment underlies the implicit assumption that every student can succeed. On the one hand, they assume that this form of feedback offers less certainty because it requires the flexibility to accommodate and adjust individual changes in the learning process but, on the other, its being person-centred promotes a higher impact on students' outcomes, teachers' self-efficacy and overall satisfaction for all the participants in the learning process (thus including parents).

\section{Teachers' values and social skills}

Moving from the cognitive constructs to social ones, it seems relevant to mention what has been observed to have almost non-significant impact on boasting students' outcomes: the qualification background (Palardy \& Rumberger, 2008). Being an expert in the subject is a fundamental requirement, and it goes uncontested that teaching implies a certain level of expertise in the relevant field of knowledge. However, the extension of teachers' personal curricula does not produce any significant change in students' performance. This is woth mentioning because, when it is referred to values and social skills, it is a fact that there is no common, recognizable curriculum that certifies teachers' competences on the matter.

There have been some timid steps toward a more holistic overview on teachers' professionalism. Australia, for 
instance, has undergone a process of renovation which included the introduction of values as an explicitly taught academic subject across the country (DEST, 2005). To implement this change, a redefinition of the soft skills required in the teaching profession is fundamental and consequently the whole training process had to be reformulated and recalibrated. More specifically, an intense debate has revolved around how the formation of values develops throughout the ages, and how to intervene effectively within the class-group via good practice and pedagogy (Halstead \& Taylor, 2000). The main issue is the identification of "shared" values in multi-ethnic and multicultural societies, where every individual is required to find a compromise and a common ground in order to build their own identity as citizen while minimizing the conflicts.

The crux of the matter lies on the lack of consensus in literature on what values are. However, one element that seems to be commonly accepted recognises them as an important asset for reaching happiness and contentment in everybody's life.

A rather broad and inclusive distinction has been advanced by Fries and colleagues (2007). Three main streams operate in educational psychology as an umbrella for different researchers and theories on values, namely object- or task-specific values, domain values and general values. The first field investigates values in relation with specific objects or goals; the second mostly refers to school subjects; the third addresses values in a more universal connotation, general and transferable. What many scholars have agreed upon is that they are often developing along a binary continuum, mostly on a two or more dimensions.

A research performed within a Taiwanese sample investigated the learning performance of students when controlling teachers-students values' congruence (Lai, 2015). Remarkably, the author was able to support that values in education have two qualifying dimensions, one explicit and one implicit. According to this dichotomy, the first can be associated to the academic achievements while the second refers to the general well-being in the school context. As expected, teacher-student congruence on explicit learning values was a positive predictor of results in the three academic skills tested (comprehensive analytic, general analytic and mathematical analytic abilities). However, what came as a surprise was a significative negative effect when predicting achievements through the congruence of implicit values. That opens a number of questions on the nature of these values, their measurement and their relevance in an academic context.

Assessing value transmission constitutes a key element when addressing teachers' influence exerted through role modelling. But how can teachers, and the society itself, succeed at grading something which is mainly not visible?

In his study regarding the Citizenship curriculum in the British School System, Pike (2007) offered a solid critique towards the formal standardized testing system when applied to such constructs. The tension between what is highlighted as important in tests and the daily content which is built throughout the school community by all its members makes the implementation of better forms of evaluation a priority.

An interesting work of Jennings and Greenberg (2009) also covered the important impact that Social and Emotional Competence in educators exerts both on students and themselves. While previous researchers focused their investigation on the lasting effects from childhood into adulthood (Pederson, Fatcher, \& Eaton, 1978), through several developmental stages (Denham, 1998), in their paper they could advance a rather unexpected link between these soft skills and the risk of burn-out: being able to master this set of competences provides teachers with more robust mental and physical resistance to cope with the work-load required by the job-description and the demands from the environment. The overall model that is offered covers several important constructs that are mutually empowering or undermining a prosocial classroom setting. Teachers' social and emotional competence and well-being can reach out to nurture every single student's well-being as well, but this channel is embedded in a wider context where the whole school context and the classroom itself weights in making it difficult to tackle each past separately and independently. However, caring for the educators is clearly an essential requirement for being able to competently foster this positive attitude among students. 


\section{Teachers' modelling role}

The converging point of all the aforementioned component of teachers' professionalism is the possibility to recognise a connection between the teachers' persona and the students' developing self.

The importance of imitative learning has been widely recognized since Bandura experimentally manipulated this psychological mechanism in his studies on aggression (Bandura, 1961). Even though the core nature of imitative learning is intrinsically perceptual-motor, "abstract sociocultural knowledge about imitative models may play an important role in imitation" (Losin and al. 2015, p. 107).

Children are more likely to generalize observed types of behaviour when they witness a positive and desirable outcome. They are also selective in whom they decide to copy (Boyd and Richerson, 1985). The imitative learning process, then, must be considered in its multiple layers of cognitive, adaptive, social and individual components. It is not referring exclusively to a passive exposure and imitating process. There seems to be a more active involvement on the children's end and several environmental elements concur to enhance or inhibit this reciprocal process.

It is possible to place imitative learning, as it happens among humans, under the umbrella of Social Learning Strategies (Boyd \& Richerson, 1985). Those processes require a high level of metacognition, because the focus is primarily on social learning from knowledgeable agents, and the skills required to make such decisions are extremely precise. Observing and adopting aspects of teachers and peers' mindsets require quite advanced cognitive competences and introspection.

The role of teachers when modelling values and social skills is not so univocal and well-known. It is considered to exert an implicit influence. Several surveys aimed at teenagers found that the main explicit models are family members and peers with little to no mention of teachers and educators. However, few studies have attempted at gathering evidence about the transmission of values through teachers (Van Oudenhoven et al. 2008, Fallona 2000). An important conceptual distinction runs between modelling as habituation (and/or condition) and modelling as education and emulation: the latter involves a personal adherence of students to the virtues they recognise in their teachers as relevant and important in what they want to become (Vos, 2018). It is not simple mimicry, but rather a cognitive process and an emotional decision. Moreover, it allows students to go beyond the contingent situation they are witnessing or experiencing, and it enables them to derive from one of the possible examples of good practice their original interpretation and re-enaction.

Imitation is also a strong bond within the group because it identifies each member as similar to others. A strong confirm of this inclusion mechanism can be observed in the "black sheep effect" (Marquez and al. 1988). It has been observed (and replicated in several studies) that breaches of social norms are more stigmatized when the perpetrator is a member of the in-group rather than an outsider. The fellow members tend to excuse somebody who is not fully aware of the conformative set of rules forming the shared values which are constituting the group identity. This leniency is not applied to somebody who should already be informed and adhere to them. This dynamic is easily recognizable in a classroom setting and teachers are active and authoritative agents that contribute to uphold the code of behaviour shared among the pupils.

\section{Conclusions}

At the end of this excursus, some boundaries must be considered and made explicit.

Among the different disciplines which are contributing to this topic, religion has been willingly overlooked. It has not been an easy decision and it remains a debatable one. However, in consideration of a pluralistic and potentially incompatible variety of religious beliefs and stemming moral laws, it has been reckoned that this reflection on teaching values and social competences should maintain an a-religious approach. Different school systems (do not) offer their own access to religious education, and other formative bodies, primarily the families and the "churches", oversee what and how to offer it, in their own fashion and through specific 
channels.

Another limitation can be observed in the target population that has been mainly addressed: the studies considered for this overview were investigating several human and professional characteristics which eventually merged in a global insight of what teachers' modelling role means. Though, this category is both the object and the intended final user of these reflections. At the very beginning, it has been acknowledged that a corpus of research was devoted to other agents within the school (such as administration bodies, students, families, and society) that are equally involved and responsible when creating an environment promoting successful outcomes for the educational actions. This parallel literature has a legit concurrent importance, but its inclusion would have added complexity and, possibly, an overload of elements to be handled.

In conclusion, the four main areas that have been connected are all interacting with each other, and they shape the daily action of any educator. Taking them apart is a mental exercise because they mostly happen simultaneously. For sake of clarity, a scientific foundation for each of them has been attempted, but it should be remembered that all the people working in schools have a peculiar embodiment of them, balancing and merging each and every-one in an attempt to respond adequately to the historical and contextual challenges that they experience in their job.

\section{References:}

1. Bandura, A., Ross, D., \& Ross, S. A. (1961). Transmission of aggression through imitation of aggressive models. Journal of Abnormal and Social Psychology, 63(3), 575-582.

2. Bandura, A. (1997). Self-efficacy: The exercise of control. New York: W. H. Freeman and Company.

3. Boyd, R., \& Richerson, P. (1985). Culture and the evolutionary process. Chicago: University 26 of Chicago Press.

4. Denham, S. A. (1998). Emotional development in young children. Guilford Press.

5. Department of Education, Science and Training (DEST) (2005). National framework for values education in Australian schools. Canberra: DEST.

6. Fallona, C. (2000). Manner in teaching: a study in observing and interpreting teachers' moral virtues. Teaching and Teacher Education, 16, 681-695.

7. Flecha, R. (2011). The dialogic sociology of education. International Studies in Sociology of Education, 21(1).

8. Fries, S., S. Schmid, and M. Hofer. 2007. On the Relationship Between Value Orientation, Valences, and Academic Achievement. European Journal of Psychology of Education, 22(2), 201-16.

9. Gerrard, J. (2017). The refugee crisis, non-citizens, border politics and education. Discourse: Studies in the Cultural Politics of Education, 38(6).

10. Gilead, T. (2017). Education's role in the economy: towards a new perspective. Cambridge Journal of Education, 47(4).

11. Halstead, J. M., Taylor, M. J. (2000). Learning and teaching about values: A review of recent research. Cambridge Journal of Education, 30(2), 169-202.

12. Hanushek, E. A., \& Rivkin, S. G. (2010). Generalizations about using value-added measures of teacher quality. American Economic Review, 100, 267-271. 
13. Hornby, G., Blackwell, I. (2018). Barriers to parental involvement in education: an update. Educational Review, 70(1), 109-119. DOI: 10.1080/00131911.2018.1388612

14. Jennings, P. A., \& Greenberg, M. T. (2009). The prosocial classroom: Teacher social and emotional competence in relation to student and classroom outcomes. Review of educational research, 79(1), 491-525.

15. Kim, L. E., Dar-Nimrod, I., \& MacCann, C. (2018). Teacher personality and teacher effectiveness in secondary school: Personality predicts teacher support and student self-efficacy but not academic achievement. Journal of Educational Psychology, 110(3), 309-323. DOI:10.1037/edu0000217

16. Kikas, E. e., Peets, K. k., \& Hodges, E. h. (2014). Collective student characteristics alter the effects of teaching practices on academic outcomes. Journal of Applied Developmental Psychology, 35(4), 273-283. DOI:10.1016/j.appdev.2014.04.004

17. Kyriakides, L., \& Creemers, B. P. (2008). Using a multidimensional approach to measure the impact of classroom-level factors upon student achievement: A study testing the validity of the dynamic model. School effectiveness and school improvement, 19(2), 183-205.

18. Lai, T. (2015). Effects of Student-Teacher Congruence on Students' Learning Performance: A Dyadic Approach. Social Science Quarterly (Wiley-Blackwell), 96(5), 1424-1435. DOI:10.1111/ssqu.12215

19. Losin, E. A. R., Woo, C. W., Krishnan, A., Wager, T. D., lacoboni, M., \& Dapretto, M. (2015). Brain and psychological mediators of imitation: sociocultural versus physical traits. Culture and Brain, 3(2), 93-111.

20. Marin, L.M., Halpern, D.F. (2011). Pedagogy for developing critical thinking in adolescents: Explicit instruction produces greatest gains. Thinking Skills and Creativity, 6(1), 1-13. DOI:10.1016/j.tsc.2010.08.002.

21. Moses, I., Berry, A., Saab N., Admiraal, W. (2017). Who wants to become a teacher? Typology of studentteachers' commitment to teaching. Journal of Education for Teaching, 43(4), 444-457. DOI:10.1080/02607476.2017.1296562

22. Müller, C.M., Hofmann, V., Begert, T., Cillessen, A.H.N. (2018). Peer influence on disruptive classroom behavior depends on teachers' instructional practice. Journal of Applied Developmental Psychology, 56, 99108. DOI:10.1016/j.appdev.2018.04.001

23. Ning, H. h., Lee, D., \& Lee, W. (2015). Relationships between teacher value orientations, collegiality, and collaboration in school professional learning communities. Social Psychology of Education, 18(2), 337-354. DOI:10.1007/s11218-015-9294-x

24. Nuutila, K., Tuominen, H., Tapola, A., Vainikainen, M.P., Niemivirta, M. (2018). Consistency, longitudinal stability, and predictions of elementary school students' task interest, success expectancy, and performance in mathematics. Learning and Instruction, 56, 73-83. DOI:10.1016/j.learninstruc.2018.04.003

25. Oudenhoven, J.P. van, Blank, A., Leemhuis, F., Pomp, M., \& Sluis, A.F. (2008). Nederland deugd [Dutch virtue]. Assen, The Netherlands: Van Gorcum.

26. Palardy, G.J., Rumberger, R.W. (2008). Teacher Effectiveness in First Grade: The Importance of Background Qualifications, Attitudes, and Instructional Practices for Student Learning. Educational Evaluation and Policy Analysis, 30(2), 111-140. DOI:10.3102/0162373708317680

27. Patrick, C. L. (2011). Student Evaluations of Teaching: Effects of the Big Five Personality Traits, Grades and the Validity Hypothesis. Assessment \& Evaluation in Higher Education, 36(2), 239-249. 
28. Pedersen, E., Faucher, T. A., \& Eaton, W. (1978). A new perspective on the effects of first-grade teachers on children's subsequent adult status. Harvard Educational Review, 48(1), 1-31.

29. Pike, M. A. (2007). Values and Visibility: The Implementation and Assessment of Citizenship Education in Schools. Educational Review, 59(2), 215-229.

30. Reynolds, D., Sammons, P., De Fraine, B., Van Damme, J., Townsend, T., Teddlie, C., \& Stringfield, S. (2014). Educational effectiveness research (EER): A state-of-the-art review. School Effectiveness and School Improvement, 25(2), 197-230.

31. Rockoff, J. E., Jacob, B. A., Kane, T. J., \& Staiger, D. O. (2011). Can you recognize an effective teacher when you recruit one? Education Finance and Policy, 6(1), 43-74.

32. Rotter, J. B. (1966). Generalized expectancies for internal versus external control of reinforcement. Psychological Monographs, 80, 1-28.

a. Ryerson, R., (2017). Creating possibilities: studying the student experience. Educational Research, 59(3), 297315. DOI:10.1080/00131881.2017.1343091

33. Tschannen-Moran, M., Hoy, A. W., \& Hoy, W. K. (1998). Teacher efficacy: Its meaning and measure. Review of Educational Research, 68, 202-248.

a. Tschannen-Moran, M., Woolfolk Hoy, A. (2001). Teacher efficacy: capturing an elusive construct. Teaching and Teacher Education, 17(7), 783-805. DOI: 10.1016/S0742-051X(01)00036-1

b. Van der Heijden, H.R.M.A., Geldens, J.J.M., Beijaard, D., Popeijus, H.L. (2015). Characteristics of teachers as change agents. Teachers and Teaching, 21(6), 681-699. DOI:10.1080/13540602.2015.1044328

34. Veiga-Neto, A. (2017). Education and pedagogy: a Foucauldian perspective. Educational Philosophy and Theory, 49(7).

35. Vos, P. H. (2018). Learning from exemplars: emulation, character formation and the complexities of ordinary life. Journal of Beliefs \& Values, 39(1), 17-28. 